BULLETIN OF ENVIRONMENTAL SCIENCE \&
Website: http://journal.hibiscuspublisher.com/index.php/BESSM/index
PUBLISHER

\title{
Kinetic Analysis of the Adsorption of Chromium onto Calcium Alginate Nanoparticles
}

\author{
Bilal Ibrahim Dan-Iya ${ }^{1 *}$, Salihu Yahuza ${ }^{2}$ and Ibrahim Alhaji Sabo ${ }^{3}$ \\ ${ }^{1}$ College of Health Sciences and Technology Kano, Kano, Nigeria. \\ ${ }^{2}$ Department of Microbiology and Biotechnology, Faculty of Science, Federal University Dutse, \\ PMB 7156, Dutse, Jigawa State, Nigeria. \\ ${ }^{3}$ Department of Microbiology, Faculty of Pure and Applied Sciences, Federal University Wukari, PMB 1020, \\ Wukari, Taraba State, Nigeria. \\ *Corresponding author: \\ Bilal Ibrahim Dan-Iya, \\ College of Health Sciences and Technology Kano, \\ Kano, \\ Nigeria. \\ Email: bidaniya@gmail.com
}

\section{HISTORY \\ Received: $23^{\text {rd }}$ Sep 2021 \\ Received in revised form: $24^{\text {th }}$ Nov 2021 \\ Accepted: $12^{\text {th }}$ Dec 2021}

\section{KEYWORDS}

Adsorption

Kinetics

Chromium

Calcium Alginate

Nanoparticles

\begin{abstract}
The widespread use of chromium in industrial applications such as leather tanning, metallurgy, electroplating, and refractory materials has resulted in it being one of the most harmful trace elements to be introduced into surface and ground waters. The sorption isotherm of chromium sorption onto calcium alginate nanoparticles were analyzed using three models - pseudo- ${ }^{\text {st }}$, pseudo- $2^{\text {nd }}$ and Elovich, and fitted using non-linear regression. The Elovich model was the poorest in fitting the curve based on visual observation followed by the pseudo- $1^{\text {st }}$ order. Statistical analysis based on root-mean-square error (RMSE), adjusted coefficient of determination $\left(\operatorname{adj} R^{2}\right)$, bias factor $(\mathrm{BF})$, accuracy factor $(\mathrm{AF})$, corrected AICc (Akaike Information Criterion), Bayesian Information Criterion (BIC) and Hannan-Quinn information criterion (HQC) that showed that the pseudo-1ST order model is the best model. Kinetic analysis using the pseudo-1st order model at $400 \mathrm{mg} / \mathrm{L}$ 4-BDE gave a value of equilibrium sorption capacity $q_{e}$ of $31.89 \mathrm{mg} \mathrm{g}^{-1}$ (95\% confidence interval from 30.37 to 33.42 ) and a value of the pseudo-1 st-order rate constant, $k_{l}$ of 0.22 (95\% confidence interval from 0.019 to 0.025 ). Further analysis is needed to provide proof for the chemisorption mechanism usually tied to this kinetic.
\end{abstract}

\section{INTRODUCTION}

Because of its extensive usage in industrial applications like as leather tanning, metallurgy, electroplating, and refractory chromium is one of the most harmful trace elements introduced into surface waters and ground waters. The rising number of studies published regarding chromium toxicity over the past ten years demonstrates the increasing number of attempts to show and remediate chromium-bearing pollution in the environment. Using standard procedures, such as chemical precipitation, ion exchange, membrane filtration, coagulation/flocculation, and electrochemical treatment, trace elements may be removed from wastewaters [1-5].

These approaches, on the other hand, are inefficient and result in enormous amounts of waste production. Sorption technologies [6] are being considered as alternatives for the treatment of water polluted by metals. As the name implies, sorption is the process by which sorbate is transferred from its liquid phase to the surface of a sorbent. Different parameters, such as $\mathrm{pH}$, temperature, the kind and quantity of sorbent used, starting metal concentration, ionic strength, as well as the presence of other pollutants, influence sorption efficacy. Physical (physiosorption) and/or chemical (chemisorption) interactions are formed between the sorbent and the sorbate in response to the attraction forces between the two. Whereas in the physiosorption process, the sorbate attaches to the sorbent surface by weak forces such as van der Waals forces [6-10].

The removal of trace elements from freshwater can be accomplished using a variety of sorbents, including nanomaterials with various forms of coating and chemical synthesis methods, as well as other approaches [11-16]. Nanomaterials, which are defined as materials and structures with a minimum size of 1-100 $\mathrm{nm}$ and a minimum thickness of 1-100 nm, exhibit a wide range of mechanical, optical, magnetic, and chemical characteristics when compared to particles and macroscopic surfaces with a comparable thickness. These properties are highly reliant on the form, size, surface features, and internal structure of the particle, and they are distinguishable from those of macroscopic surfaces and particles of equivalent composition in that they are not dependent on these factors. 
Moreover, the physical-chemical features of the fluid in which nanoparticles are absorbed or desorption are dependent on the sorption processes of nanomaterials, which should be considered while designing nanomaterials [17-19]. Whenever nanomaterials are used as sorbents for the removal of toxic elements from wastewater, they must meet a number of requirements. These requirements include being nontoxic, having high sorption capacities, being selective to low concentrations of contaminants, being simple to remove the sorbed contaminant from their surface, and being recyclable. This question has been investigated whether harmful trace elements can be removed from aqueous solutions by using a variety of nanomaterials, including carbon nanotubes and carbon-based material composites such as graphene, nanometals or metal oxides, and polymeric sorbents. To date, all of these nanomaterials have met these requirements, with the exception of carbon nanotubes and carbon-based material composite materials such as graphene [20-23]. In a previous study, the sorption of chromium on calcium alginate nanoparticles was studied using linearized kinetic models which disrupt the error structure of the data and hindered efficient inference and comparison with current biosorption data that have begun to capitalize on the computing power that allow nonlinear regression to be carried out at ease.

Correct assignment of the kinetics and isotherms of biosorption is critical for understanding the mechanism of biosorption. This is especially true for understanding the mechanism of biosorption. The use of linearization to smooth out a clearly nonlinear curve causes the error structure of the data to be disrupted. This makes estimating the uncertainty of the parameters of the kinetics, which is generally provided in the form of a 95 percent confidence interval range, much more challenging [24]. Aside from that, the linearization procedure results in the introduction of error into the independent variable as well. Additionally, changes in the weights assigned to each data point may occur, which typically results in discrepancies in the fit parameter values between both the linear and nonlinear versions of the kinetics model, depending on the data set [25]. Thus, the aim of this study is to remodel the data using nonlinear regression.

\section{METHODS}

\section{Data acquisition and fitting}

Data from Figure 4 from a published work [26] were digitized using the software Webplotdigitizer 2.5 [27]. The data were then nonlinearly regressed using the curve-fitting software CurveExpert Professional software (Version 1.6). Digitization using this software has been acknowledged for its reliability $[28,29]$. The data were then nonlinearly regressed using the curve-fitting software CurveExpert Professional software (Version 1.6) using several models (Table 1).

Table 1. Kinetic models utilized in this study.

\begin{tabular}{lcl}
\hline Model & Equation & Reference \\
\hline Pseudo-1st order & $q_{t}=q_{e}\left(1-e^{-K_{1} t}\right)$ & {$[30]$} \\
Pseudo-2nd order & $q_{t}=\frac{K_{2} q_{e}{ }^{2} t}{\left(1+K_{2} q_{e} t\right)}$ & {$[31]$} \\
& $q_{t}=\frac{1}{\beta \ln \alpha \beta}+\frac{1}{\beta \ln t}$ & {$[32]$}
\end{tabular}

\section{Statistical analysis}

A battery of statistical discriminatory tests such as corrected AICc (Akaike Information Criterion), Bayesian Information Criterion (BIC), Hannan and Quinn's Criterion (HQ), RootMean-Square Error (RMSE), bias factor (BF), accuracy factor
(AF) and adjusted coefficient of determination $\left(R^{2}\right)$ were utilized in this work.

The RMSE was calculated according to Eq. (1), [24], and smaller number of parameters is expected to give a smaller RMSE values. $n$ is the number of experimental data, $O b_{i}$ and $P d_{i}$ are the experimental and predicted data while $p$ is the number of parameters.

$R M S E=\sqrt{\frac{\sum_{i=1}^{n}\left(P d_{i}-O b_{i}\right)^{2}}{n-p}}$

As $R^{2}$ or the coefficient of determination ignores the number of parameters in a model, the adjusted $R^{2}$ is utilized to overcome this issue. In the equation (Eqns. 2 and 3), the total variance of the y-variable is denoted by $S_{y}^{2}$ while RMS is the Residual Mean Square.

$$
\begin{aligned}
& \text { Adjusted }\left(R^{2}\right)=1-\frac{R M S}{s_{Y}^{2}} \\
& \text { Adjusted }\left(R^{2}\right)=1-\frac{\left(1-R^{2}\right)(n-1)}{(n-p-1)}
\end{aligned}
$$

The AICc is calculated as follows (Eqn. 4), where $p$ signifies the quantity of parameters and $n$ signify the quantity of data points. To handle data having a high number of parameters or a smaller number of values corrected Akaike information criterion (AICc) is utilized [33].A model with a smaller value of AICc is deemed likely more correct [33]. The Akaike Information Criterion (AIC) is based on the information theory. It balances between the goodness of fit of a particular model and the complexity of a model [34].

$A I C C=2 p+n \ln \left(\frac{R S S}{n}\right)+2(p+1)+\frac{2(p+1)(p+2)}{n-p-2}$

Aside from AICc, Bayesian Information Criterion (BIC) (Eqn. 5) is another statistical method that is based on information theory. This error function penalizes the number of parameters more strongly than AIC [35].

$B I C=n \cdot \ln \frac{R S S}{n}+k \cdot \ln (n)$

(Eqn. 5)

A further error function method based on the information theory is the Hannan-Quinn information criterion (HQC) (Eqn. 6). The HQC is strongly consistent unlike AIC due to the $\ln \ln n$ term in the equation [33];

$H Q C=n \times \ln \frac{R S S}{n}+2 \times k \times \ln (\ln n)$

Further error function analysis that originates from the work of Ross [36] are the Accuracy Factor (AF) and Bias Factor (BF). These error functions test the statistical evaluation of models for the goodness-of-fit but do not penalize for number of parameter (Eqns. 7 and 8).

$$
\begin{aligned}
& \text { Bias factor }=10^{\left(\sum_{i=1}^{n} \log \frac{\left(P d_{i} / O b_{i}\right)}{n}\right)} \\
& \text { Accuracy factor } \left.=10^{\left(\sum_{i=1}^{n} \log \frac{\mid\left(P d_{i} / O b_{i}\right)}{n}\right)}\right)
\end{aligned}
$$

Another error function analysis is the evidence ratio regarding the difference between the two lowest AICc values (Eqn. 9), 
where if it is the same, then each model will have an equal chance of being true.

If the difference in AICc scores is 6.0, model A has a 95\% chance of being correct, making it $20(95 / 5)$ times more likely than model B to be correct [24].

$$
P_{A}=\frac{e^{0.5 \Delta}}{1+e^{0.5 \Delta}}
$$

\section{RESULTS AND DISCUSSION}

It is possible that a lack of chromium in the environment will have negative repercussions for the metabolism of both plants and animals. Chromium pollution from industrial sources, on the other hand, is becoming more significant in recent years. Chromium contamination in wastewater may be caused by a variety of sources, including the dye and pigment industries, wood preservation, electroplating, and leather tanning, among others. Chromium tanning processes are used in more than 80 percent of the country's tanneries, according to official figures. Approximately the vast majority of these facilities, according to current estimates, release untreated sewage into the environment. New chemicals are now being released into the environment as a consequence of current industrial activity patterns, which is interfering with the usual flow of materials in the ecosystem [3741].

As defined by the International Atomic Energy Agency (IAEA), heavy metals are defined as metals having a density more than or equal to $5 \mathrm{~g} / \mathrm{mL}$ and are classed as such. Heavy metal pollution of water is a significant concern in today's society, and it is a worldwide issue. According to the findings, the absorption of heavy metals by organisms is more reliant on the concentration of free metal ions in solution than on the concentration of total metal in solution, which was previously established. Since improved correlations between metal absorption and the concentration of free metal ions or labile metals have been established, the bioavailability and toxicity of heavy metals are now primarily governed by the number of heavy metals present in free metal ions, rather than the amount of heavy metals present in free metal ions. Because of their nonbiodegradability and high quantities of heavy metals, they are hazardous to human health and should be avoided.

World Health Organization (WHO) has recognised a handful of metals as the most important threats to human health in the contemporary period, according to the organisation. Cadmium, chromium, cobalt, copper, lead, nickel, mercury, zinc, arsenic, and tin are just a few of the heavy metals that may be found in the environment. In terms of neurotoxicity, the three most dangerous metals are mercury, cadmium, and lead, which are the most toxic of the three [42-46].

The absorption kinetics data were analyzed using three models - pseudo- $1^{\text {st }}$, pseudo- $2^{\text {nd }}$ and Elovich, and fitted using non-linear regression. The Elovich model was the poorest in fitting the curve based on visual observation followed by Pseudo2nd order (Figs. 1-3). Statistical analysis based on root-meansquare error (RMSE), adjusted coefficient of determination $\left(\operatorname{adj} R^{2}\right)$, bias factor $(\mathrm{BF})$, accuracy factor $(\mathrm{AF})$, corrected $\mathrm{AICc}$ (Akaike Information Criterion), Bayesian Information Criterion (BIC) and Hannan-Quinn information criterion (HQC) that showed that the pseudo-first-order model is the best (Table 2). The calculated evidence ratio was 133 with an AICc probability value of 0.99 indicating that the best model was at least 133 times better than the nearest best model, which was pseudo- $1^{\text {st }}$. Further analysis is needed to provide proof for the mechanism usually tied to this kinetic. The sorption of chromium at various concentrations on calcium alginate nanoparticles was then fitted using the pseudo- $1^{\text {st }}$ model (Fig. 4).

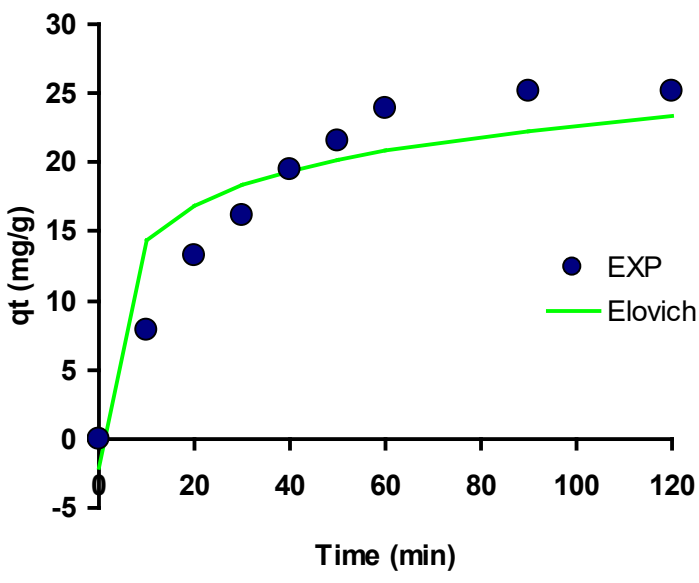

Fig. 1. Kinetics of the sorption of chromium on calcium alginate nanoparticles as modelled using the Elovich model.

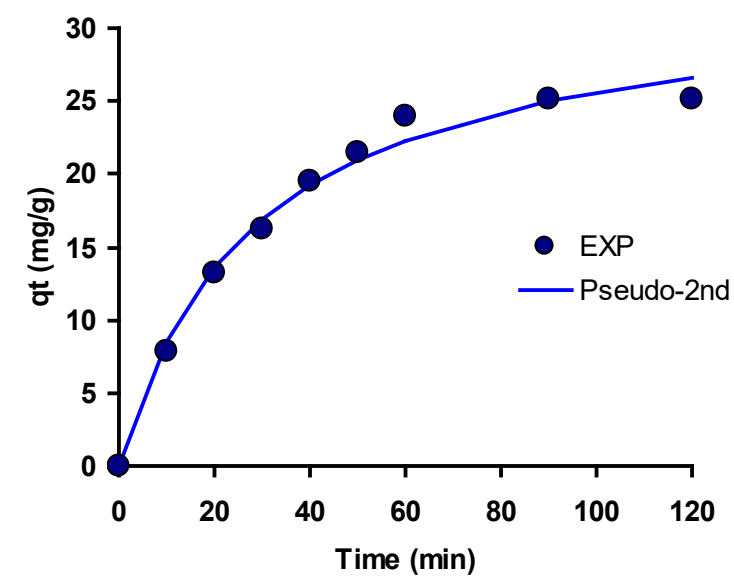

Fig. 2. Kinetics of the sorption of chromium on calcium alginate nanoparticles as modelled using the pseudo- ${ }^{\text {st }}$ order model.

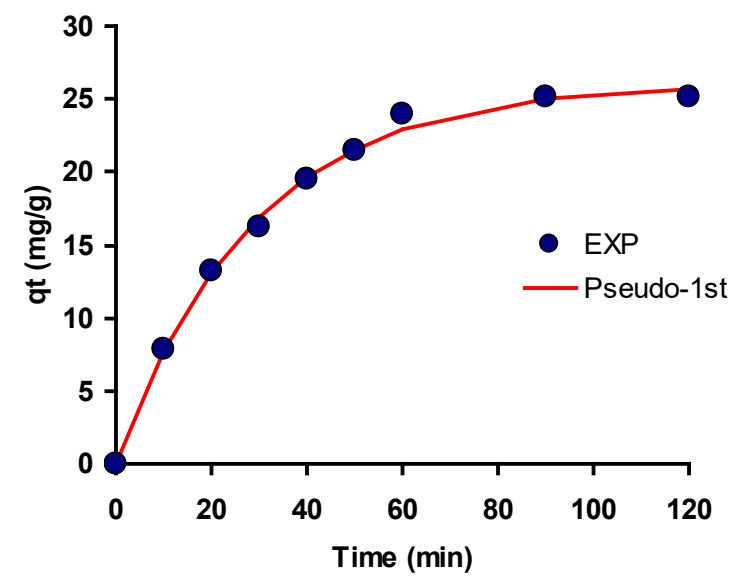

Fig. 3. Kinetics of the sorption of chromium on calcium alginate nanoparticles as modelled using the pseudo- $2^{\text {nd }}$ order model 
3. Wang G, Zhang B, Li S, Yang M, Yin C. Simultaneous microbial reduction of vanadium $(\mathrm{V})$ and chromium (VI) by Shewanella loihica PV-4. Bioresour Technol. 2017 Mar 1;227:353-8.

4. Cheng J, Gao J, Zhang J, Yuan W, Yan S, Zhou J, et al. Optimization of Hexavalent Chromium Biosorption by Shewanella putrefaciens Using the Box-Behnken Design. Water Air Soil Pollut. $2021 \mathrm{Feb} 22 ; 232(3): 92$.

5. Blagojev N, Vasić V, Kukić D, Šćiban M, Prodanović J, Bera O. Modelling and efficiency evaluation of the continuous biosorption of $\mathrm{Cu}(\mathrm{II})$ and $\mathrm{Cr}(\mathrm{VI})$ from water by agricultural waste materials. J Environ Manage. 2021 Mar 1;281:111876.

6. Basirun AA, Khudri MAMRS, Yasid NA, Othman AR, Johari WLW, Shukor MY, et al. Kinetic analysis for the removal of copper using Durvillaea antarctica. J Environ Microbiol Toxicol. 2019 Jul 31;7(1):32-5.

7. Abubakar A. Test for Outlier and Normality of the Residuals for the Pseudo-1st Order Kinetic Modelling of Glyphosate Adsorption onto Palm Oil Fronds. Bull Environ Sci Sustain Manag. 2020 Dec 31;4(2):18-22.

8. Ammar C, El-Ghoul Y, Jabli M. Characterization and valuable use of Calotropis gigantea seedpods as a biosorbent of methylene blue. Int J Phytoremediation. 2021;23(10):1085-94.

9. Javed I, Javed T, Khan MN. A characteristic study of Zea mays L. (sweet corn) cobs for synthetic dye degradation from aqueous media. Water Sci Technol. 2021;83(1):52-62.

10. Pourang N, Rezaei M. Biosorption of copper from aqueous environment by three aquatics-based sorbents: A comparison of the relative effect of seven important parameters. Bioresour Technol Rep. 2021 Sep 1;15:100718.

11. Cai T, Ma M, Liu H, Li J, Hou J, Gong B. Preparation of monodisperse magnetic surface molecularly imprinted polymers for selective recognition of lincomycin hydrochloride in milk. J Liq Chromatogr Relat Technol. 2019;42(13-14):459-67.

12. Gupta GS, Kansara K, Shah H, Rathod R, Valecha D, Gogisetty S, et al. Impact of humic acid on the fate and toxicity of titanium dioxide nanoparticles in Tetrahymena pyriformis and zebrafish embryos. Nanoscale Adv. 2019;1(1):219-27.

13. Liu Z, Gao Y, Jin L, Jin $\mathrm{H}, \mathrm{Xu} \mathrm{N}, \mathrm{Yu} \mathrm{X}$, et al. Core-Shell Regeneration Magnetic Molecularly Imprinted Polymers-Based SERS for Sibutramine Rapid Detection. ACS Sustain Chem Eng. 2019;7(9):8168-75.

14. Qin H, Cheng H, Long $\mathrm{C}, \mathrm{Wu} \mathrm{X}$, Chen $\mathrm{Y}$, Hu M, et al. Efficient adsorption of $\mathrm{Hg}$ (II) from aqueous solution by $\mathrm{N}, \mathrm{S}$ co-doped MnFe2O4@C magnetic nanoparticles. Water Sci Technol. 2020;81(6):1273-82.

15. Tan N-D, Lan C, Yin J-H, Meng L, Xu N. Selective Detection of Trace Metronidazole by Using a Magnetic Molecularly Imprinted Polymer-based Fluorescent Probe. Bull Korean Chem Soc. 2020;41(1):60-5.

16. Vicente-Martínez Y, Caravaca M, Soto-Meca A. Simultaneous adsorption of mercury species from aquatic environments using magnetic nanoparticles coated with nanomeric silver functionalized with L-Cysteine. Chemosphere. 2021;282.

17. Baby R, Saifullah B, Hussein MZ. Carbon Nanomaterials for the Treatment of Heavy Metal-Contaminated Water and Environmental Remediation. Nanoscale Res Lett [Internet]. 2019;14(1). Available from: https://www.scopus.com/inward/record.uri?eid=2-s2.0$85075110878 \&$ doi $=10.1186 \% 2$ fs $11671-019-3167$ 8\&partnerID=40\&md5=b895bb2ee5966fb22c84d2fc67d975ec

18. Zhang C, Wang W, Duan A, Zeng G, Huang D, Lai C, et al. Adsorption behavior of engineered carbons and carbon nanomaterials for metal endocrine disruptors: Experiments and theoretical calculation. Chemosphere. 2019;222:184-94.

19. Wang Y, Zhao W, Tian X, Song H, Gao R, Tang X, et al. Highefficiency recognition and detection of sulindac in sewage using hydrophilic imprinted resorcinol-formaldehyde resin magnetic nano-spheres as SPE adsorbents combined with HPLC. Chem Eng J. 2020;392.

20. Mueller NC, Nowack B. Nanoparticles for remediation: Solving big problems with little particles. Elements. 2010;6(6):395-400.

21. Li Y, Hong M, Miaomiao, Bin Q, Lin Z, Cai Z, et al. Novel composites of multifunctional Fe3O4@Au nanofibers for highly efficient glycoprotein imprinting. J Mater Chem B. 2013;1(7):1044-51.
22. Fernandes T, Soares SF, Trindade T, Daniel-da-Silva AL. Magnetic hybrid nanosorbents for the uptake of paraquat from water Nanomaterials. 2017 Mar;7(3):68.

23. Yang K, Wang J, Chen X, Zhao Q, Ghaffar A, Chen B. Application of graphene-based materials in water purification: From the nanoscale to specific devices. Environ Sci Nano. 2018;5(6):126497.

24. Motulsky HJ, Ransnas LA. Fitting curves to data using nonlinear regression: a practical and nonmathematical review. FASEB J Off Publ Fed Am Soc Exp Biol. 1987;1(5):365-74.

25. Tran HN, You S-J, Hosseini-Bandegharaei A, Chao H-P. Mistakes and inconsistencies regarding adsorption of contaminants from aqueous solutions: A critical review. Water Res. 2017 Sep $1 ; 120: 88-116$.

26. Sadiq A, Choubey A, Bajpai AK, Sadiq A, Choubey A, Bajpai AK Biosorption of chromium ions by calcium alginate nanoparticles. J Chil Chem Soc. 2018;63(3):4077-81.

27. Rohatgi A. WebPlotDigitizer http://arohatgi.info/WebPlotDigitizer/app/ Accessed June 2 2014; 2015.

28. Halmi MIE, Shukor MS, Johari WLW, Shukor MY. Mathematical modelling of the degradation kinetics of Bacillus cereus grown on phenol. J Environ Bioremediation Toxicol. 2014;2(1):1-5.

29. Khare KS, Phelan Jr FR. Quantitative comparison of atomistic simulations with experiment for a cross-linked epoxy: A specific volume-cooling rate analysis. Macromolecules. 2018;51(2):56475.

30. Lagergren S. Zur theorie der sogenannten adsorption gelöster stoffe (About the theory of so-called adsorption of soluble substances). K Sven Vetenskapsakademiens Handl. 1898;24(4):1-39.

31. Ho YS, McKay G. Pseudo-second order model for sorption processes. Process Biochem. 1999 Jul 1;34(5):451-65.

32. Zeldovich J. Über den mechanismus der katalytischen oxydation von $\mathrm{CO}$ an $\mathrm{MnO}_{2}$. Acta Physicochim URSS. 1934;1:364-499.

33. Burnham KP, Anderson DR. Model Selection and Multimodel Inference: A Practical Information-Theoretic Approach. Springer Science \& Business Media; 2002. 528 p.

34. Akaike H. New look at the statistical model identification. IEEE Trans Autom Control. 1974;AC-19(6):716-23.

35. Kass RE, Raftery AE. Bayes Factors. J Am Stat Assoc. 1995 Jun 1;90(430):773-95.

36. Ross T, McMeekin TA. Predictive microbiology. Int J Food Microbiol. 1994;23(3-4):241-64

37. Bendezu S, Oyague J, Romero A, García R, Muñoz Y, Escalona N Chromium adsorption from tannery effluents by activated carbons prepared from coconut shells by chemical activation with $\mathrm{KOH}$ and ZNCL $<$ inf $>2</$ inf $>$. J Chil Chem Soc. 2005;50(4):677-84.

38. Srivastava $\mathrm{S}$, Ahmad AH, Thakur IS. Removal of chromium and pentachlorophenol from tannery effluents. Bioresour Technol. 2007;98(5):1128-32.

39. Zhao C, Yang Q, Chen W, Teng B. Removal of hexavalent chromium in tannery wastewater by Bacillus cereus. Can J Microbiol. 2012 Jan 1;58(1):23-8.

40. Sharmila S, Rebecca Jeyanthi L, Saduzzaman M. Biodegradation of tannery effluent using Prosopis juliflora. Int J ChemTech Res. 2013;5(5):2186-92.

41. Huang G, Wang W, Liu G. Simultaneous chromate reduction and azo dye decolourization by Lactobacillus paracase CL1107 isolated from deep sea sediment. J Environ Manage. $2015 \mathrm{Ju}$ 1;157:297-302.

42. Thacker U, Madamwar D. Reduction of toxic chromium and partial localization of chromium reductase activity in bacterial isolate DM1. World J Microbiol Biotechnol. 2005;21(6-7):891-9.

43. Rezaie-Boroon MH, Gnandi K, Folly KT-M. Presence and distribution of toxic trace elements in water and sediments of the southern Togo Rivers watershed, West Africa. Fresenius Environ Bull. 2011;20(7 A):1853-65.

44. Phuong NTK, Khoa NC. Evaluation of heavy metals in tissue of shellfish from Can Gio coastline in Ho Chi Minh city, Vietnam. Asian J Chem. 2013;25(15):8552-6.

45. Mohamed KN. Heavy metals distribution in seabed sediment at Golok Central and Golok Barat gas fields, Sarawak. Bull Environ Sci Sustain Manag. 2014 Dec 3;2(2):48-52.

46. Pathania D. Heavy metals: Sources, toxicity and remediation techniques [Internet]. 2016. $1-310$ p. Available from: 
https://www.scopus.com/inward/record.uri?eid=2-s2.0$85022002221 \&$ partnerID $=40 \& \mathrm{md} 5=\mathrm{e} 10 \mathrm{f} 1 \mathrm{dda} 46896008 \mathrm{cc} 6 \mathrm{~d} 8 \mathrm{bd} 8 \mathrm{f}$ 21 ecf83

47. Yuan G, Zhao B, Chu KH. Adsorption of fluoride by porous adsorbents: Estimating pore diffusion coefficients from batch kinetic data. Environ Eng Res. 2020;25(5):645-51.

48. Li H, He J, Chen K, Shi Z, Li M, Guo P, et al. Author Response to Comment on: Dynamic Adsorption of Sulfamethoxazole from Aqueous Solution by Lignite Activated Coke. Materials. 2021 Jan;14(4):868.

49. $\mathrm{Hu}$ Q, Pang S, Wang D. In-depth Insights into Mathematical Characteristics, Selection Criteria and Common Mistakes of Adsorption Kinetic Models: A Critical Review. Sep Purif Rev. 2021 Jul 1;0(0):1-19.

50. González-López ME, Laureano-Anzaldo CM, Pérez-Fonseca AA, Arellano M, Robledo-Ortíz JR. A Critical Overview of Adsorption Models Linearization: Methodological and Statistical Inconsistencies. Sep Purif Rev. 2021 Aug 1;0(0):1-15.

51. Qurie M, Khamis M, Manassra A, Ayyad I, Nir S, Scrano L, et al. Removal of Cr(VI) from aqueous environments using micelle-clay adsorption. Sci World J. 2013;Article ID 942703:7.

52. Khamizov RKh, Sveshnikova DA, Kucherova AE, Sinyaeva LA. Kinetic model of batch sorption processes: Comparing calculated and experimental data. Russ J Phys Chem A. 2018 Oct 1;92:20328.

53. Özacar M. Response to comment on "Two-stage batch sorber design using second-order kinetic model for the sorption of metal complex dyes onto pine sawdust" by Dr. Y.-S. Ho, Biochem. Eng. J. 21 (2004) 39-45. Biochem Eng J. 2005 May 1;23(3):293.

54. Kumar KV, Porkodi K, Rocha F. Comments on "Removal of lead from aqueous solution using Syzygium cumini L.: equilibrium and kinetic studies." J Hazard Mater. 2007 Aug 17;147(1-2):677-8.

55. Lima EC, Cestari AR, Adebayo MA. Comments on the paper: a critical review of the applicability of Avrami fractional kinetic equation in adsorption-based water treatment studies. Desalination Water Treat. 2016 Sep 1;57(41):19566-71.

56. Periasamy K, Namasivayam C. Removal of copper(II) by adsorption onto peanut hull carbon from water and copper plating industry wastewater. Chemosphere. 1996 Feb 1;32(4):769-89.

57. Tariq M, Durrani AI, Farooq U, Tariq M. Efficacy of spent black tea for the removal of nitrobenzene from aqueous media. J Environ Manage. 2018;223:771-8.

58. Yue T, Guo C, Yuan Y, Wang Z, Luo Y, Wang L. Adsorptive removal of patulin from apple juice using ca-alginate-activated carbon beads. J Food Sci. 2013;78(10):T1629-35.

59. Sohrabi H, Ameri E. Adsorption equilibrium, kinetics, and thermodynamics assessment of the removal of the reactive red 141 dye using sesame waste. Desalination Water Treat. 2016;57(38):18087-98.

60. Salman Naeem M, Javed S, Baheti V, Wiener J, Javed MU, Ul Hassan SZ, et al. Adsorption kinetics of Acid Red on activated carbon web prepared from acrylic fibrous waste. Fibers Polym. 2018;19(1):71-81.

61. Low KS, Lee CK, Tan KK. Biosorption of basic dyes by water hyacinth roots. Bioresour Technol. 1995 Jan 1;52(1):79-83. 